\title{
Clinical Outcomes of Surgical Treatments for Traumatic Spinal Injuries due to Snowboarding
}

\author{
Takahiro Masuda $^{1}$, Kei Miyamoto ${ }^{2}$, Kazuhiko Wakahara $^{3}$, Kazu Matsumoto ${ }^{1}$, Akira Hioki ${ }^{4}$, \\ Tetsuya Shimokawa ${ }^{2}$, Katsuji Shimizu ${ }^{5}$, Shinji Ogura ${ }^{6}$, Haruhiko Akiyama ${ }^{1}$ \\ ${ }^{1}$ Department of Orthopaedic Surgery, Gifu University Graduate School of Medicine, Gifu, Japan \\ ${ }^{2}$ Department of Regional Medicine and Musculoskeletal Science, Gifu University Graduate School of Medicine, Gifu, Japan \\ ${ }^{3}$ Division of Orthopaedic Surgery, Ibi Kousei Hospital, Gifu, Japan \\ ${ }^{4}$ Spine Center, Matsunami General Hospital, Gifu, Japan \\ ${ }^{5}$ Spine Center, Gifu Municipal Hospital, Gifu, Japan \\ ${ }^{6}$ Advanced Critical Care Center, Gifu University Graduate School of Medicine, Gifu, Japan
}

\begin{abstract}
Study Design: Retrospective study.
Purpose: To assess treatment outcomes of snowboarding-related spinal and spinal cord injuries.

Overview of Literature: Snowboarding-related spinal or spinal cord injury have a great impact on social and sporting activities.

Methods: A retrospective review of 19 cases of surgically treated snowboard-related injury was done. Analyzed parameters included site of injury, type of fracture, peri- and postoperative complications, pre- and postoperative neurological status, activities of daily living, and participation in sports activities at the final follow-up.

Results: The major site of injury was the thoracolumbar junction caused by fracture-dislocation (13/19 cases). The remaining 6 cases had cervical spine injuries. Over $60 \%$ of the patients had Frankel A and B paralysis. All patients were surgically treated by posterior fusion with instrumentation. Five underwent additional anterior fusion. Surgical outcome was restoration of ambulatory capacity in 12 patients (63.2\%). Ultimately, 15 patients (78.9\%) could return to work. Patients with complete paralysis upon admission showed reduced ambulatory capacity compared to those with incomplete paralysis. None of the patients again participated in any sports activities, including snowboarding.

Conclusions: Snowboarding-related spinal or spinal cord injury has a great impact on social as well as sports activities. It is necessary to enhance promotion of injury prevention emphasizing the snowboarders' responsibility code.
\end{abstract}

Keywords: Snowboarding; Spinal injury; Surgical treatment; Clinical outcomes

\section{Introduction}

The huge popularity of snowboarding has rapidly changed the scene of ski slopes worldwide. Data from Europe and North America have indicated that as much as $50 \%$ of the mountain slopes are occupied by snow- boarders in some resorts [1]. Unfortunately, this surge in popularity has been accompanied by an increase in the incidence of snowboarding-related trauma [2,3], notably head and spinal injuries [4-6]. Spinal cord injuries, along with severe head injuries, are the most devastating and costly types of injury associated with recreational sports.

Received May 12, 2014; Revised Jul 14, 2014; Accepted Aug 3, 2014

Corresponding author: Kei Miyamoto

Department of Regional Medicine and Musculoskeletal Science, Gifu University Graduate School of Medicine,

1-1 Yanagido, Gifu 501-1194, Japan

Tel: +81-58-230-6333, Fax: +81-58-230-6334, E-mail: kei@bg8.so-net.ne.jp 
Table 1. Profiles of snowboarders who sustained spinal and/or spinal cord injuries ( $n=19)$

\begin{tabular}{|c|c|c|c|c|c|c|c|c|}
\hline Case & $\begin{array}{l}\text { Age } \\
\text { (yr) }\end{array}$ & Sex & Cause & $\begin{array}{c}\text { Period until } \\
\text { operation (day) }\end{array}$ & $\begin{array}{c}\text { Period of } \\
\text { follow-up (mo) }\end{array}$ & $\begin{array}{l}\text { Level of } \\
\text { injury }\end{array}$ & Type of fracture & $\begin{array}{c}\text { Paralysis } \\
\text { (Frankel grade) }\end{array}$ \\
\hline 1 & 19 & Male & Fall & 47 & 50 & $\mathrm{C} 2 / 3$ & Fracture-dislocation & $E$ \\
\hline 2 & 22 & Male & Jump & 5 & 62 & C5 & Burst fracture & B \\
\hline 3 & 21 & Male & Jump & 10 & 82 & C5 & Burst fracture & D \\
\hline 4 & 17 & Male & Jump & 14 & 40 & $\mathrm{C} 5 / 6$ & Fracture-dislocation & C \\
\hline 5 & 26 & Male & Crash & 0 & 15 & C5, 6 & Burst fracture & C \\
\hline 6 & 25 & Male & Jump & 10 & 27 & $\mathrm{C} 6,7$ & Burst fracture & B \\
\hline 7 & 25 & Male & Jump & 0 & 16 & Th10/11 & Fracture-dislocation & A \\
\hline 8 & 29 & Male & Jump & 0 & 13 & Th11/12 & Fracture-dislocation & A \\
\hline 9 & 32 & Male & Jump & 1 & 39 & Th11/12 & Fracture-dislocation & A \\
\hline 10 & 26 & Male & Jump & 0 & 49 & Th11/12 & Fracture-dislocation & A \\
\hline 11 & 29 & Male & Fall & 1 & 75 & Th11/12 & Fracture-dislocation & A \\
\hline 12 & 27 & Male & Jump & 0 & 86 & Th11/12 & Fracture-dislocation & A \\
\hline 13 & 24 & Male & Jump & 0 & 99 & Th11/12 & Fracture-dislocation & B \\
\hline 14 & 22 & Male & Jump & 0 & 5 & Th12/L1 & Fracture-dislocation & A \\
\hline 15 & 22 & Male & Fall & 0 & 50 & Th12/L1 & Fracture-dislocation & D \\
\hline 16 & 26 & Male & Jump & 0 & 74 & Th12/L1 & Fracture-dislocation & A \\
\hline 17 & 22 & Male & Jump & 0 & 86 & Th12/L1 & Fracture-dislocation & B \\
\hline 18 & 29 & Female & Fall & 24 & 39 & L1 & Burst fracture & $E$ \\
\hline 19 & 22 & Male & Jump & 0 & 16 & L1 & Burst fracture & C \\
\hline
\end{tabular}

Head and spinal injuries account for an estimated 4\%$28 \%$ of all snow sports-related injuries, with the majority of cases being mild in nature [7]. Generally, spinal injuries associated with snowboarding tend to occur in young men (94.4\%), due to jumping failures (83.3\%), and at the thoracolumbar junction (66.7\%) accompanied by severe paralysis classified as Frankel A or B (83.3\%) [8]. Although there have been reports of snowboarding injuries, little information is available regarding their neurological involvement, including clinical course after operations, return to work, and return to playing sports. We performed a retrospective study of our experience and clinical outcomes in treating 19 patients with traumatic spinal cord injury, associated with vertebral fractures resulting from snowboarding accidents.

\section{Materials and Methods}

\section{Subjects}

Subject information is summarized in Table 1. Nineteen patients (18 men and 1 woman) with spinal injuries due to snowboarding who underwent operations at our institution between 1997 and 2009 were assessed retrospectively. Diagnoses were made by physical examination and imaging information from X-ray and computed tomography (CT). Presently, patients with severe spinal injuries are transferred by helicopter through primary emergency hospitals; transport to our hospital takes only 20 to 30 minutes. Our prefecture has many ski facilities serviced by the highway and the number of participants coming from other nearby prefectures is increasing. Therefore, most of the injured patients tend to be residents from other prefectures. To facilitate the early transfer of these patients to their home area, they undergo operations with implantation as soon as possible depending on their general condition. Even in patients with complete spinal cord injury, it is prudent to perform operations earlier to secure damaged neural structures and promote early rehabilitation. A delay may have led to complications, such as pneumonia, pressure sores, and venous thrombosis. All patients received intravenous methylprednisolone within 8 hours of injury in accordance with a published protocol [9]. 
On admission to our hospital, informed consent is routinely sought for the use of patient data in clinical studies. The present study was approved by the Institutional Review Board of Gifu University Graduate School of Medicine.

\section{Assessment of clinical outcomes}

The clinical features of these patients were reviewed with respect to the nature of their spinal cord injuries, including the site of injury, fracture pattern, and neurological status. Neurological status was graded according to the Frankel scale (grade A, complete; B, sensory only; C, motor useless; D, motor useful; E, recovery) [10]. The patients were also classified into two groups with regard to primary paralysis. The complete group consisted of Frankel grade $\mathrm{A}$ and the incomplete group consisted of the other grades. For assessment of surgical interventions, the operation time, blood loss, and peri- and postoperative complications were assessed. Changes in neurological improvement, status of daily life, work and sports activities, and participation in any type of sports activity, including snowboarding, were assessed. These outcomes were compared between the Complete and incomplete groups.

\section{Statistical analysis}

Differences between patients in the complete and incomplete groups were assessed statistically using Stat View ver. 5.0 (SAS Institute, Cary, NC, USA). Final neurological status of Frankel type was assessed by chi-square test, while ambulatory capacity and other status were assessed by Fisher's exact probability test. In all analyses, $p<0.05$ was taken to indicate statistical significance.

\section{Results}

\section{Clinical features}

Clinical features are summarized in Table 1. The average age of patients was 24.5 years ( \pm standard deviation [SD], 3.8; range, 17-32 years). The injuries were due to jumping failures in 14 cases, falls in 4 cases, and a crash in 1 case. The average period of postoperative follow-up was 49.6 months ( $\pm \mathrm{SD}, 31.6$; range, 5-99 months). The average period from admission to operation was 5.4 days ( \pm SD 12.1; range, $0-47$ days). While most of the patients underwent an emergency operation on the day of injury, 2 cases without neurologic injury (Frankel type E, cases 1 and 18) (Table 1) underwent surgery later. The major site of injury was the thoracolumbar junction (13 cases), followed by the cervical spine in 6 cases. The fracture patterns were burst fractures in 1 of the 13 injuries at the thoracolumbar junction and 4 of the 6 cervical injuries. The others were all anterior fracture-dislocation. Paralysis was classified as Frankel type A ( $n=8), B(n=4), C(n=3)$, $D(n=2)$, and $E(n=2)$. More than $60 \%$ of the patients sustained severe paralysis (Frankel type A or B) (Fig. 1). All of the patients classified as Frankel type A had sustained fracture-dislocation at the thoracolumbar junction caused by high energy impact.

\section{Operative assessment (Table 2)}

Eleven of the 19 patients underwent an emergency operation. Only 1 patient with cervical injury underwent one-stage operation with anterior and posterior fusion, while the others underwent posterior fusion during the first operation. Four patients with thoracolumbar junction injury underwent anterior fusion at the second operation. The operation time was $247( \pm$ SD 91) minutes at the first operation $(n=19)$ and $252 \pm 122$ minutes at the second operation $(n=4)$. Blood loss was $784 \pm 493 \mathrm{~g}$ in the first operation and $556 \pm 522 \mathrm{~g}$ in the second operation. We performed autotransfusion if possible. Two patients developed pneumonia postoperatively. These patients had cervical spine injury, Frankel type B paralysis, and underwent operations on several occasions. Three of 4

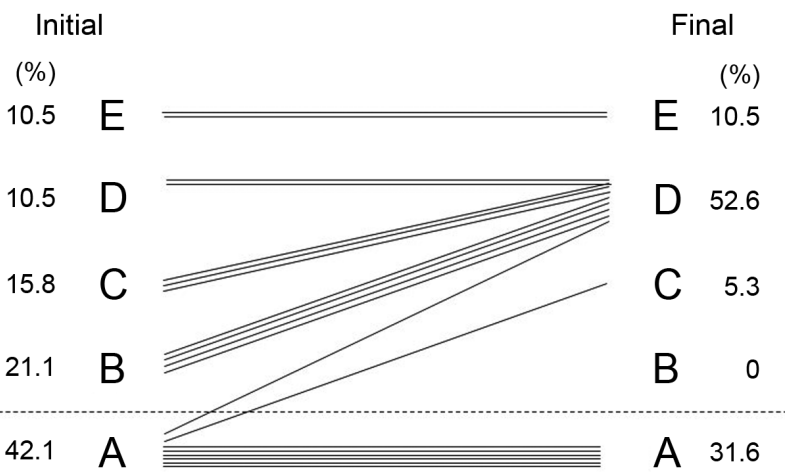

Fig. 1. Improvement of paralysis (Frankel type classification) (n=19). The paralysis tended to be Frankel type A or D. The patients classified into Frankel type A had complete paralysis. The others had incomplete paralysis. The recovery rate was different between the two types of paralysis. 
Table 2. Surgical outcomes of the injured snowboarders $(n=19)$

\begin{tabular}{|c|c|c|c|c|c|c|c|c|}
\hline Case & Method & $\begin{array}{c}\text { Operation } \\
\text { time } 1 \mathrm{st} / 2 \mathrm{nd} \\
\text { (hr:mm) }\end{array}$ & $\begin{array}{l}\text { Blood loss } \\
\text { 1st/2nd (g) }\end{array}$ & Complications & $\begin{array}{c}\text { Final paralysis } \\
\text { (Frankel } \\
\text { grade) }\end{array}$ & $\begin{array}{l}\text { Return } \\
\text { to work }\end{array}$ & $\begin{array}{l}\text { Participation } \\
\text { in sports }\end{array}$ & $\begin{array}{l}\text { Participation in } \\
\text { snowboarding }\end{array}$ \\
\hline 1 & PF & $4: 02$ & 810 & Pneumonia, decubitus & D & No & No & No \\
\hline 2 & PF & $4: 09$ & 1615 & - & D & Yes & No & No \\
\hline 3 & PF & $3: 32$ & 975 & UTI & A & No & No & No \\
\hline 4 & PF & $5: 24$ & 585 & - & D & Yes & No & No \\
\hline 5 & PF & $4: 30$ & 1197 & - & A & No & No & No \\
\hline 6 & PF & $3: 48$ & 1386 & - & C & No & No & No \\
\hline 7 & $P F+A F(2)^{a)}$ & 2:40/7:00 & 190/985 & - & D & Yes & No & No \\
\hline 8 & $P F+A F(2)^{a)}$ & $2: 55 / 4: 25$ & $450 / 1,029$ & - & D & Yes & No & No \\
\hline 9 & PF & $7: 40$ & 833 & - & A & Yes & No & No \\
\hline 10 & $P F+A F(2)^{a)}$ & $3: 35 / 2: 25$ & $1,500 / 60$ & UTI & A & Yes & No & No \\
\hline 11 & $P F+A F(2)^{a)}$ & 2:45/3:00 & $1,429 / 150$ & - & $\mathrm{D}$ & Yes & No & No \\
\hline 12 & PF & $5: 10$ & 470 & Pneumonia & D & Yes & No & No \\
\hline 13 & PF & $3: 20$ & 430 & UTI & D & Yes & No & No \\
\hline 14 & PF & $3: 11$ & 1214 & UTI, decubitus & A & Yes & No & No \\
\hline 15 & PF & $3: 16$ & 770 & - & A & Yes & No & No \\
\hline 16 & $P F+A F(1)^{b)}$ & $4: 00$ & 103 & - & $D$ & Yes & No & No \\
\hline 17 & $\mathrm{AF}$ & $4: 55$ & 650 & - & $E$ & Yes & No & No \\
\hline 18 & PF & $7: 40$ & 123 & & D & Yes & No & No \\
\hline 19 & PF & $1: 52$ & 178 & & $E$ & Yes & No & No \\
\hline
\end{tabular}

$\mathrm{PF}$, posterior fusion; UTI, urinary tract infections, $\mathrm{AF}$, anterior fusion.

${ }^{\text {al }} \mathrm{PF}+\mathrm{AF}$ (2), 2-stage procedure; ${ }^{\text {bl } P F+A F}$ (1), 1-stage procedure.

patients who developed urinary tract infections (UTI) belonged to the complete group. The severe bladder disorder due to the spinal cord injuries in these patients may have led to a tendency to develop UTI.

3. Postoperative activities of daily living (ADL), sports, and participation in sports activities in patients with complete and incomplete paralysis at the onset of injury

1) Neurological assessment and ADL after surgery (Table 3, Fig. 1)

The primary paralysis in 6 of 8 patients with Frankel type A did not improve, while that in the other 2 patients improved to Frankel type D. Most of the patients classified as Frankel type $\mathrm{B}$ or $\mathrm{C}$ showed improvement in paralysis to Frankel type D (Fig. 1). Finally, 7 of 8 patients in the complete group required a wheelchair at the final follow- up. The other 12 patients (63.2\%) could walk with or without assistance at the final follow-up, including 7 patients initially classified as Frankel type B or C. Fifteen patients (78.9\%) returned to work, but none participated in sports activities since their spinal injury. There were no significant differences in the rates of returning to work or participation in sport activities between the Complete and incomplete groups (Table 3). Furthermore, 13 patients $(68.4 \%)$ still had neurological bladder disorder, comprising 7 of 8 patients in the complete group $(87.5 \%)$ and 6 of 11 patients in the incomplete group (54.5\%).

\section{Case reports}

\section{1) Case 1}

A 26-year-old man had incomplete tetraplegia (Frankel type C) after crashing into a tree while snowboarding. The results of X-ray and CT scan showed burst fracture 
Table 3. Postoperative activities of daily living, sports, and participation in sports in patients with complete and incomplete paralysis at the onset of injury

\begin{tabular}{|c|c|c|c|}
\hline \multirow[b]{2}{*}{ Characteristic } & \multicolumn{2}{|c|}{ Paralyses at the onset of injuries } & \multirow[b]{2}{*}{$p$-value ${ }^{\text {a }}$} \\
\hline & $\begin{array}{l}\text { Complete (Frankel A) } \\
\qquad n=8\end{array}$ & $\begin{array}{l}\text { Incomplete (Frankel B, C, D, E) } \\
\qquad \mathrm{n}=11\end{array}$ & \\
\hline Final neurological status & & & 0.001 \\
\hline Frankel A & 6 & 0 & \\
\hline Frankel B & 0 & 0 & \\
\hline Frankel C & 1 & 0 & \\
\hline Frankel D & 1 & 2 & \\
\hline Frankel E & 0 & 9 & \\
\hline Ambulatory Capacity & & & 0.001 \\
\hline Wheelchair (\%) & 7 & 0 & \\
\hline Walk with or without assistance (\%) & 1 & 11 & \\
\hline \multicolumn{4}{|l|}{ Other status } \\
\hline Return to work (n [\%]) & $5(62.5)$ & $10(90.9)$ & 0.176 \\
\hline Driving (n [\%]) & $3(37.5)$ & $9(81.8)$ & 0.067 \\
\hline Participation in sports (n [\%]) & $0(0)$ & $0(0)$ & 1.667 \\
\hline Participation in snowboarding (n [\%]) & $0(0)$ & $0(0)$ & 1.667 \\
\hline
\end{tabular}

a) Fisher's exact test.
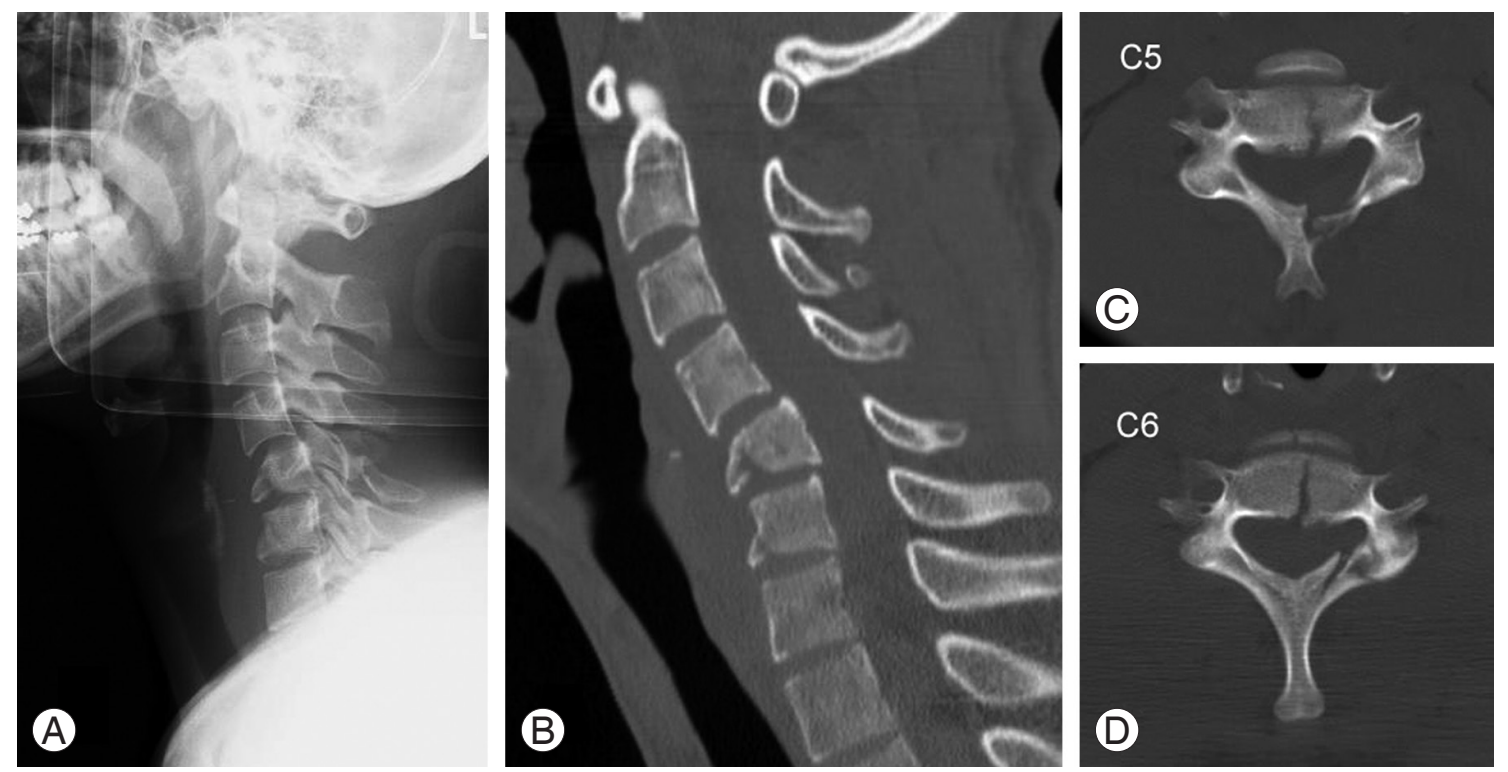

Fig. 2. Case 1: preoperative $\mathrm{X}$-ray (A) and computed tomography (B-D) of the cervical spine. C5 and C6 had burst fracture and developed kyphotic deformity.

(flexion-compression) in C5 and C6 (Fig. 2). On the same day as the injury, the patient received intravenous administration of methylprednisolone, and emergency operation for posterior spinal decompression and fusion with instrumentation (Fig. 3). Fifteen months postoperatively, he could walk without any assistance and returned to work. 

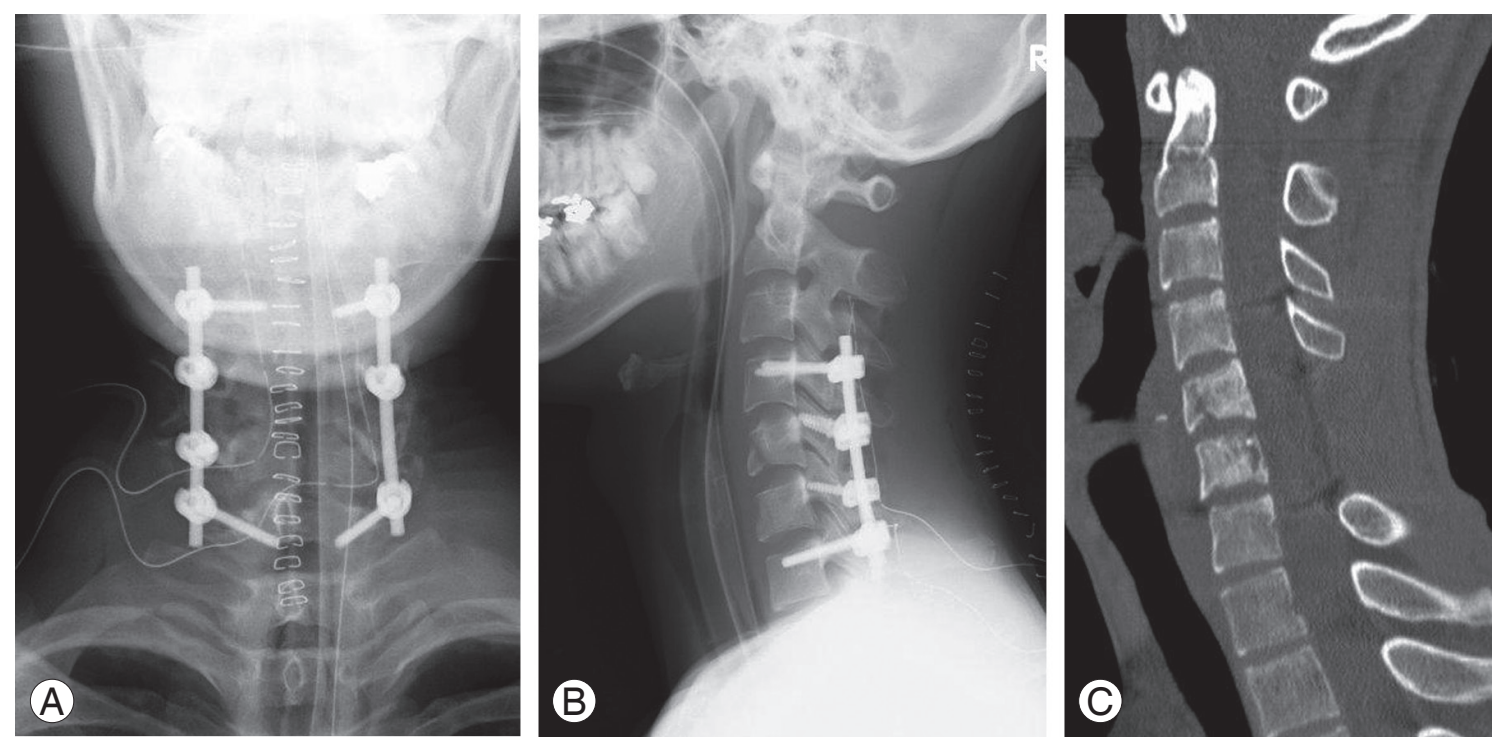

Fig. 3. Case 1: postoperative X-ray (A, B) and computed tomography (C) of cervical spine. From C4 to C7, the vertebrae were fused with implantation. The alignment was improved.
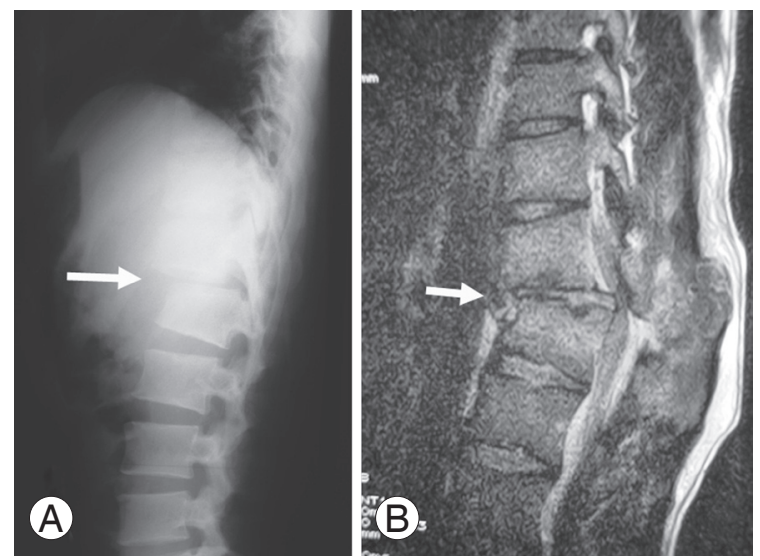

Fig. 4. Case 2: preoperative $\mathrm{X}$-ray (A) and magnetic resonance imaging (B) of thoracolumbar junction. The spine developed kyphotic deformity.

\section{2) Case 2}

A 26-year-old man had complete paralysis in both legs (Frankel type A) after a jumping failure while snowboarding. The results of X-ray and magnetic resonance imaging scan showed distractive-flexion between Th11 and Th12 (Fig. 4). On the same day as the injury, the patient received intravenous administration of methylprednisolone, and emergency operation for posterior spinal reposition and fusion with instrumentation. After 2 months, he underwent anterior decompression and fusion. The posterior implants were removed when bone union was achieved (Fig. 5). Paralysis recovered to Frankel type D.
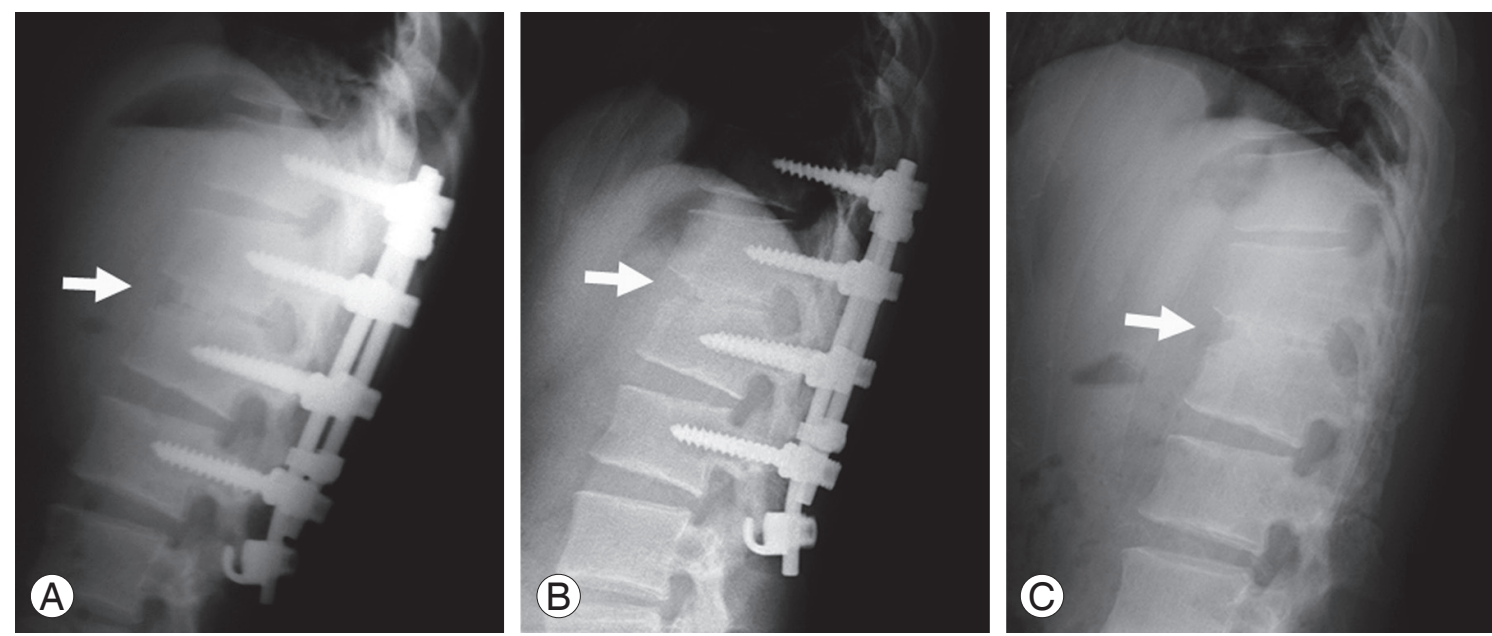

Fig. 5. Case 2: postoperative X-ray after first posterior fusion (A), second anterior fusion (B), and removal of implants (C). The second operation was performed 2 months later, and the removal of the implants was performed 20 months later. Bone union was achieved. 


\section{Discussion}

This is the first report regarding the clinical course of paralysis related to snowboarding and their ADL. Importantly, all injured snowboarders included in the present study stated that they no longer participated in snowboarding or any other sports activity since their injuries. As physically handicapped individuals can still participate in many types of sport, these results clearly illustrated the severe physical and psychological impact of spinal and spinal cord injuries on snowboarders.

\section{Characteristics of snowboarders who sustain spinal injuries}

Wakahara et al. [8] reported that most injured snowboarders were young men, with thoracolumbar junction injury caused by jumping, and over half of the patients showed severe paralysis classified as Frankel type A or B. Siu et al. [11] suggested that young male snowboarders have an elevated risk of neck and head injury. Seino et al. [12] suggested that the predominance of male patients may reflect the aggressive and reckless snowboarding behavior of young men. Chow et al. [13] also documented the close association between the performance of aerial maneuvers by snowboarders and the propensity to injure the head, abdomen, and spine. In the present study, the characteristics of patients were compatible with those described in previous reports. In all injuries related to snowboarding, $4.7 \%$ were vertebral injuries and $0.3 \%$ were spinal cord injuries [14]. These proportions were 4 times higher than those related to skiing [14]. The major fracture pattern in snowboarding is fracture-dislocation, which requires high energy, and tends to accompany severe spinal cord injury $[8,12]$. In the present study, the same characteristics were obtained.

\section{Operative intervention}

There is no consensus in the literature regarding the timing of surgery for spinal cord injurys. Cengiz et al. [15] reported significantly better recovery when paralysis was incomplete and decompression was performed within 8 hours. Furlan et al. [16] suggested early surgical intervention was safe and feasible and could improve clinical and neurological outcomes and reduce health care costs. In contrast, McKinley et al. [17] suggested early spinal surgery ( $<72$ hours after injury) reduces pulmonary complications. However, there were no differences in neurological or functional improvements between the early and late surgical groups. We performed spinal operations as soon as possible to promote early rehabilitation and reduce the risk of secondary complications. In terms of neurological improvement, urgent operations may not have played a significant role in amelioration of severe paralysis, but it was presumed that they at least helped to reduce the risk of complications [17].

\section{Neurological outcomes of surgically treated snow- boarders who sustained spinal injuries}

Among the patients included in the present study, those with complete paralysis classified into Frankel type A tended not to recover at all, similar to cases reported previously [15]. Fisher's exact probability test confirmed that the patients in the complete group showed a significantly higher rate of requiring a wheelchair compared to those in the incomplete group (Table 3). The recovery rates of the patients with some paralysis were different between the Complete and incomplete groups, while it seemed that final recoveries were focused to Frankel type A and $\mathrm{D}$ (total in both, $84.2 \%$ ). Improvement of paralysis was observed in only 2 of 8 patients (25.0\%) in the complete group, but in 7 of 9 patients $(77.8 \%)$ in the incomplete group. This difference was significant, and the prognosis with regard to paralysis was markedly different between the two groups. Except in cases of complete paralysis, there was a good likelihood of regaining ambulatory capacity in the incomplete group.

\section{Performance in daily activities and sports in surgically treated snowboarders who sustained spinal injuries}

As the patients in this study could be characterized as young adults who have to work for a living and who had actively participated in sports, this study focused on their postoperative activities in both working and sporting activities. There was no significant difference in the ratio of patients who could return to work between the Complete and incomplete groups (Fig. 3). Furthermore, none of the subjects included in the present study participated in any sports activities, including snowboarding, after the spinal operations. We speculate that they were traumatized psychologically as well as physically. There were no signifi- 
cant differences in the rates of returning to driving, playing sports, and snowboarding between the Complete and incomplete groups. Thus, the results of the present study indicate that participation in work and sports activities, including snowboarding, do not depend on the degree of primary paralysis or neurological improvement, but on the degree of psychological trauma.

\section{Limitations of the present study}

There were some limitations in this study. First, we assessed only patients that had undergone surgery. Combined or comparative analyses in patients with snowboarding-related spinal or spinal cord injury who were treated conservatively may provide additional data. Second, most snowboarders are young adults. Therefore, further evaluation of marriage status, sexual life, and mental condition would also provide relevant data. Third, the number of patients included in this study was small. Further studies in larger numbers of cases will be useful to evaluate the effects of surgical intervention on paralysis.

\section{Conclusions}

We performed operations in 19 patients with unstable spinal injuries due to snowboarding. Although most of the patients who initially had paralysis still had some paralysis at the average of 4 -year follow-up, $79 \%$ of the patients returned to work. However, these spinal injuries markedly influenced their social and sports activities. It will be necessary to enhance promotion of injury prevention emphasizing the snowboarders' responsibility code.

\section{Conflict of Interest}

No potential conflict of interest relevant to this article was reported.

\section{References}

1. Bladin C, Giddings P, Robinson M. Australian snowboard injury data base study. A four-year prospective study. Am J Sports Med 1993;21:701-4.

2. Abu-Laban RB. Snowboarding injuries: an analysis and comparison with alpine skiing injuries. CMAJ 1991;145:1097-103.

3. O’Neill DF, McGlone MR. Injury risk in first-time snowboarders versus first-time skiers. Am J Sports Med 1999;27:94-7.

4. Chissell HR, Feagin JA Jr, Warme WJ, Lambert KL, King P, Johnson L. Trends in ski and snowboard injuries. Sports Med 1996;22:141-5.

5. Nakaguchi H, Fujimaki T, Ueki K, Takahashi M, Yoshida H, Kirino T. Snowboard head injury: prospective study in Chino, Nagano, for two seasons from 1995 to 1997. J Trauma 1999;46:1066-9.

6. Fukuda O, Takaba M, Saito T, Endo S. Head injuries in snowboarders compared with head injuries in skiers. A prospective analysis of 1076 patients from 1994 to 1999 in Niigata, Japan. Am J Sports Med 2001;29:437-40.

7. Levy AS, Smith RH. Neurologic injuries in skiers and snowboarders. Semin Neurol 2000;20:233-45.

8. Wakahara K, Matsumoto K, Sumi H, Sumi Y, Shimizu $\mathrm{K}$. Traumatic spinal cord injuries from snowboarding. Am J Sports Med 2006;34:1670-4.

9. Bracken MB, Shepard MJ, Collins WF, et al. A randomized, controlled trial of methylprednisolone or naloxone in the treatment of acute spinal-cord injury. Results of the Second National Acute Spinal Cord Injury Study. N Engl J Med 1990;322:1405-11.

10. Frankel HL, Hancock DO, Hyslop G, et al. The value of postural reduction in the initial management of closed injuries of the spine with paraplegia and tetraplegia. I. Paraplegia 1969;7:179-92.

11. Siu TL, Chandran KN, Newcombe RL, Fuller JW, Pik JH. Snow sports related head and spinal injuries: an eight-year survey from the neurotrauma centre for the Snowy Mountains, Australia. J Clin Neurosci 2004;11:236-42.

12. Seino H, Kawaguchi S, Sekine M, Murakami T, Yamashita T. Traumatic paraplegia in snowboarders. Spine (Phila Pa 1976) 2001;26:1294-7.

13. Chow TK, Corbett SW, Farstad DJ. Spectrum of injuries from snowboarding. J Trauma 1996;41:321-5.

14. Tarazi F, Dvorak MF, Wing PC. Spinal injuries in skiers and snowboarders. Am J Sports Med 1999;27:17780.

15. Cengiz SL, Kalkan E, Bayir A, Ilik K, Basefer A. Timing of thoracolomber spine stabilization in trauma patients; impact on neurological outcome and clinical course. A real prospective (rct) randomized controlled study. Arch Orthop Trauma Surg 2008;128:959-66. 
16. Furlan JC, Noonan V, Cadotte DW, Fehlings MG. Timing of decompressive surgery of spinal cord after traumatic spinal cord injury: an evidence-based examination of pre-clinical and clinical studies. J Neurotrauma 2011;28:1371-99.
17. McKinley W, Meade MA, Kirshblum S, Barnard B. Outcomes of early surgical management versus late or no surgical intervention after acute spinal cord injury. Arch Phys Med Rehabil 2004;85:1818-25. 